\title{
Análise da condição de ingresso e evolução na carreira docente nas redes estadual de ensino do Paraná e municipal de ensino de Curitiba
}

\author{
Diana Cristina de Abreu ${ }^{1}$
}

dianacristinaabreu@gmail.com

\begin{abstract}
Resumo
Este artigo foi desenvolvido no decorrer da pesquisa intitulada "Remuneração dos professores das escolas públicas da educação básica: configurações, impactos, impasses e perspectivas". Neste trabalho, pretende-se realizar uma análise da carreira docente estabelecida nas redes estadual de ensino do Paraná e municipal de ensino de Curitiba. Na análise, priorizaramse as categorias: condição de ingresso, recrutamento dos professores e as formas de progressões salariais praticadas com base na formação dos docentes. Dessa forma, verificou-se que ambas as redes de ensino possuem formas de ingresso e progressões salariais diferenciadas; em alguns casos, elas se aproximam e em outros se afastam do que exige o ordenamento legal atualizado pelo Fundeb e pelas novas diretrizes para a carreira do magistério público, publicadas pelo Conselho Nacional de Educação em 2009.
\end{abstract}

Palavras-chave: carreira; ingresso; evolução na carreira; salário; titulação.

1 Doutoranda em Educação/UFPR, pesquisadora no NuPE/UFPR e professora da educação básica. Bolsista (2009/2010) na pesquisa do Observatório da Educação CAPES/INEP/ SECAD intitulada "Remuneração dos professores das escolas públicas da educação básica: configurações, impactos, impasses e perspectivas".

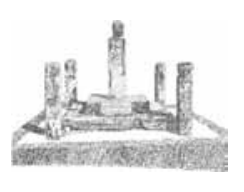




\section{Introdução}

A carreira e a remuneração docente no Brasil, ainda que sejam considerados importantes instrumentos para a valorização do magistério, ganham visibilidade em nosso país somente com o advento da nova LDB 9394/1996, Lei de Diretrizes e Bases da Educação Nacional. A LDB deixara a cargo dos vários sistemas de ensino a elaboração de políticas de valorização do magistério. No mesmo ano de 1996 e três meses antes da aprovação da LDB, havia sido aprovada a Emenda Constitucional n. 14/96, que instituiu o Fundo de Manutenção e Desenvolvimento do Ensino (Fundef). O Fundo, em princípio, visava à valorização do magistério nos estados e municípios. Diferentes literaturas apontam as positividades e negatividades dessa política de fundos no que concerne à remuneração docente. Sem dúvida, o Fundef teve caráter inédito na redistribuição e alocamento de recursos entre os entes federados, em decorrência do estabelecimento de não menos de $60 \%$ do montante arrecadado na composição do fundo para a valorização do magistério, o que é destacado por Castro (1998) como um mérito da política de fundos. Já Davies (1999) concluiu que somente a redistribuição de recursos já existentes e destinados à educação não seria suficiente para a melhoria dos padrões educacionais, nem mesmo para a valorização do magistério.

O argumento de Davies (1999) pode ser justificado à medida que a década de 90, no contexto das reformas educacionais, possa ser entendida como aquela na qual as políticas sociais passaram por crises tanto de concepção quanto propriamente de investimento público. Naquele momento, para Peroni (2003), a política educacional não estava somente sendo determinada pela redefinição do papel do Estado, mas, sobretudo, seria parte constitutiva dessa mudança.

Contraditoriamente, foi num cenário de desregulamentação/ flexibilização das relações de trabalho nas esferas públicas e privadas que algumas políticas para a valorização docente 
ganharam mais visibilidade e ordenamento jurídico nacional.

Em seguida à aprovação do Fundef e da LDB, em 1997 o Ministério da Educação e Cultura (MEC) e o Conselho Nacional de Educação (CNE) travaram um acirrado e importante debate sobre a elaboração das diretrizes nacionais para a carreira docente. No debate, surgiram discussões polêmicas sobre o custo-aluno e especialmente sobre o Piso Salarial Profissional. O resultado foi a Resolução 03/97 CNE/CEB, que mais satisfez aos interesses do MEC do que os da sociedade civil.

As legislações citadas anteriormente disciplinaram a carreira docente no país até a aprovação da Emenda Constitucional n. 53, de 2006. Por meio dela, foram alterados os artigos 30, 206, 208, 211 e 212 da Constituição Federal. A alteração fez com que o artigo 206 passasse a ter uma redação, além de contemplar a efetivação do Piso Salarial Profissional Nacional para os profissionais da educação escolar pública e definiu ainda que uma lei complementar fixaria um prazo para a elaboração ou adequação de seus planos de carreira nos âmbitos da União, dos estados, do Distrito Federal e dos municípios.

Por fim, em dezembro de 2006, foi sancionada pelo Presidente da República a lei n. 11.494/07, que instituiu o Fundeb - de que trata o artigo 60 do Ato das Disposições Constitucionais Transitórias. Em seguida, também foi sancionada a lei 11. 738/2007, que regulamentou a alínea " $\mathrm{e}$ " do inciso III, do caput do artigo 60 do Ato das Disposições Constitucionais Transitórias, para instituir o Piso Salarial Profissional Nacional para os profissionais do magistério público da educação básica.

Com as alterações na política de financiamento que se deu pela instituição do Fundeb e a sanção da Lei do Piso, as diretrizes para a carreira e a remuneração docente, expostas na Resolução 03/1997, tornaram-se extemporâneas, levando à necessidade de elaboração de novas diretrizes. Assim, por meio do Parecer CNE/CEB 9, de 2009, e da Resolução CEB/CNE 02/2009, foram fixadas as novas diretrizes para os planos de carreira e remuneração do magistério

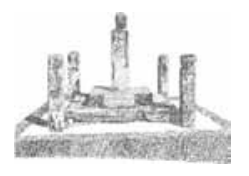


público nos estados, municípios e Distrito Federal.

As políticas inscritas na legislação brasileira descritas acima - Fundeb, Lei do Piso Nacional - e a homologação pelo CNE das Novas Diretrizes para Carreira e Remuneração do Magistério Público no Brasil são, sem dúvida, um marco para a valorização do magistério público. Em 2010, a organização da Conferência Nacional de Educação (Conae) permitiu a materialização de um processo de síntese que, por um lado, dá destaque às conquistas legais alcançadas e, por outro, demonstra os limites legais que temos e aponta para um cenário ideal de valorização do magistério.

Considerando os argumentos expostos anteriormente, neste trabalho ${ }^{2}$ pretende-se realizar uma análise comparativa da condição de ingresso e formas de progressão nas redes estadual do Paraná e municipal de Curitiba, confrontadas as deliberações da Conferência Nacional de Educação sobre as duas temáticas.

\section{Condição de ingresso, admissão e acesso ao cargo público}

Na Conae/2010, a questão da valorização do magistério público da educação básica aparece associada às condições de formação e profissionalização dos docentes e demais trabalhadores em educação. Nesse sentido, a Conferência enfatiza a necessidade de padrões mínimos de qualidade àqueles que atuam na educação básica, destacando a necessidade de uma política nacional de formação e valorização profissional, na qual se garantam o cumprimento das leis: n. 9.394/96, n. 12.014/09 e n. 11.301/2006. Atender a legislação hoje, no quesito ingresso e admissão, é admitir a necessidade de contratação por concurso público. Embora essa seja uma determinação constitucional, muitas vezes, por brechas na própria legislação, se fazem presentes formas precárias de contratações.

2 Este trabalho apresenta uma síntese realizada a partir dos instrumentos de coleta de dados elaborada no âmbito do projeto de pesquisa do Observatório da Educação (CAPES/INEP/ SECAD) intitulado "Remuneração dos professores das escolas públicas da educação básica: configurações, impactos, impasses e perspectivas". 
Da mesma forma, as diretrizes nacionais preveem o concurso como condição de ingresso e também reforçam o que é determinado no artigo 85 da lei 9394/1996, o qual dispõe que qualquer cidadão habilitado com titulação própria poderá exigir a abertura de concurso público de provas e títulos para cargo de docente de instituição pública de ensino que estiver sendo ocupado por professor não concursado por mais de seis anos.

A rede estadual de ensino do Paraná, apesar de regulamentar, no plano de carreira, o ingresso por concurso público, contrata professores em Processo Seletivo Simplificado. Essa prerrogativa de contratação precária está prevista na Lei Complementar 108/2005. Por meio dela, o estado do Paraná realiza contratação temporária para o provimento de diversos cargos de outras áreas e secretarias estaduais; portanto, o vínculo de Processo Seletivo Simplificado não é uma prerrogativa somente para os trabalhadores em educação.

No caso da rede municipal de ensino de Curitiba, o concurso público é a única forma de ingresso desde 2001. Entretanto, é permitida a dobra de jornada em Regime Integral de Trabalho. Esse Regime é discriminado na lei específica 8248/1993; ela define que a dobra será devida quando os ocupantes da carreira do magistério optarem pela dobra de jornada, ou seja, 40 horas semanais. Pelo Regime Integral de trabalho, é pago um percentual de 100\% sobre o valor do vencimento padrão percebido pelo servidor, o que serve de base de cálculo para a contribuição previdenciária.

Dessa forma, a rede estadual de ensino do Paraná, diferentemente da rede municipal de ensino, possui um processo precário de contratação de trabalhadores.

As classificações dos cargos nos planos comparados distinguemse na nomenclatura e no significado. Na rede estadual de ensino do Paraná, o cargo é de "professor" e na rede municipal de ensino de Curitiba, o cargo é de "profissional do magistério". No plano da rede estadual, está especificada a mesma concepção das Diretrizes Nacionais/2009, nas quais:

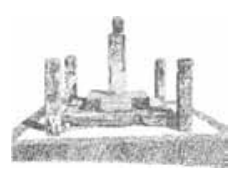


São considerados profissionais do magistério aqueles que desempenham as atividades de docência ou as de suporte pedagógico à docência, isto é, direção ou administração, planejamento, inspeção, supervisão, orientação e coordenação educacionais, exercidas no âmbito das unidades escolares de Educação Básica, em suas diversas etapas e modalidades (Educação Infantil, Ensino Fundamental, Ensino Médio, Educação de Jovens e Adultos, Educação Especial, Educação Profissional, Educação Indígena), com a formação mínima determinada pela legislação federal de Diretrizes e Bases da Educação Nacional (BRASIL, 2009).

Quanto à conceituação dos termos profissionais da educação e trabalhador da educação, a Conae/2010 apresenta a seguinte conceituação:

Vale distinguir, nessa abrangência, a conceituação dos termos trabalhadores/ as e profissionais da educação, por vezes considerados como sinônimos. $\mathrm{O}$ termo trabalhadores/as da educação se constitui como recorte de uma categoria teórica que retrata uma classe social: a dos/das trabalhadores/as. Assim, refere-se ao conjunto de todos/as os/as trabalhadores/ as que atuam no campo da educação (BRASIL, 2010, p. 77).

Já no caso do município, o plano não contempla os profissionais que atuam na educação infantil. Estes têm carreira própria, com jornada de trabalho, condição de ingresso, vencimento, remuneração e cargo diferenciado do dos professores. Para os educadores que trabalham na educação infantil, a estratégia utilizada pela prefeitura de Curitiba não é diferente da adotada em muitas prefeituras brasileiras para economizar recursos na contratação desse profissional.

A Resolução n. 02/CNE/2009 deixou a cargo dos entes federados incluir os demais profissionais da educação em planos 
de carreira unificados ou próprios, sem nenhum prejuízo aos profissionais do magistério. Nas diretrizes, então, fica claro que os entes federados terão autonomia para integrar ou não os demais profissionais nos planos de carreira.

A Conae/2010, justamente pela natureza democrática e participativa de sua composição, acenou para a unificação dos planos de carreira, abrangendo funcionários de escola, professores e especialistas em educação, assegurando remuneração digna e condizente com as especificidades de cada profissão.

\section{Formas para evolução na carreira condicionadas à formação docente}

Uma breve introdução nesta sessão torna-se oportuna para esclarecer que a evolução na remuneração nos planos de carreira costumam ser de duas formas: promoção vertical e progressão horizontal. Elas não podem ser tomadas como sinônimas, pois promoção é a elevação vertical na carreira, procedimento em que geralmente são considerados os níveis de escolarização formal do trabalhador docente e são garantidos percentuais mais elevados de ganhos remuneratórios. Já a progressão caracteriza-se pela elevação horizontal na carreira; são considerados aspectos relativos à formação continuada e em serviço dos docentes - cursos de curta duração, aperfeiçoamentos, publicações científicas e didáticas, entre outras - nesta forma, todavia, os percentuais de elevação remuneratórios são menores.

Uma das polêmicas introduzidas pelas novas diretrizes para carreira e remuneração do magistério público foi o item sobre a avaliação de desempenho como critério para progressão na carreira. Se por um lado o texto reafirma que é necessária não somente a avaliação do docente, mas todo o sistema de ensino, por outro sugere que os resultados educacionais possam ser utilizados para balizar a remuneração docente. Esse é um tema que deve ser debatido intensamente por professores, suas entidades sindicais, o poder público e a sociedade civil.

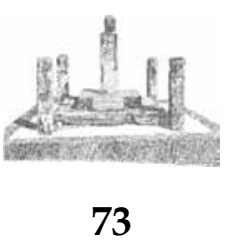


Assim, em seu artigo 5, inciso XVI, alínea c, a Resolução 02/2009 do CNE/CEB estabelece:

c) avaliação de desempenho, do profissional do magistério e do sistema de ensino, que leve em conta, entre outros fatores, a objetividade, que é a escolha de requisitos que possibilitem a análise de indicadores qualitativos e quantitativos e a transparência, que assegura que o resultado da avaliação possa ser analisado pelo avaliado e pelos avaliadores, com vistas à superação das dificuldades detectadas para o desempenho profissional ou do sistema, a ser realizada com base nos seguintes princípios:

1. para o profissional do magistério:

1.1 participação democrática - o processo de avaliação teórica e prática deve ser elaborado coletivamente pelo órgão executivo e os profissionais do magistério de cada sistema de ensino.

2. Para os sistemas de ensino:

2.1 amplitude - a avaliação deve incidir sobre todas as áreas de atuação do sistema de ensino, que compreendem:

2.1.1 a formulação das políticas educacionais; 2.1.2 a aplicação delas pelas redes de ensino; 2.1.3 o desempenho dos profissionais do magistério;

2.1.4 a estrutura escolar;

2.1.5 as condições socioeducativas dos educandos;

2.1.6 outros critérios que os sistemas considerarem pertinentes;

2.1.7 os resultados educacionais da escola (BRASIL, 2009, p. 4).

Em resposta ao documento do CNE que insere no debate esse tema com caráter tão polêmico, o texto final da Conae/2010 defendeu como critério para a valorização dos profissionais da educação a: 
para todos os trabalhadores da educação, excluindo-se qualquer fundamentação na concepção de premiação ou punição por meio, ainda, da implantação e implementação do Plano de Cargos, Carreiras e Salários, elaborado com participação paritária, considerando promoção, progressão e titulação como critérios automáticos de desenvolvimento na carreira (BRASIL, 2010, p. 96).

A reformulação das recém elaboradas Diretrizes Nacionais é sugerida no texto em grande medida, porque recomenda a avaliação de desempenho como incentivo às progressões salariais e ainda remete à possibilidade de essa avaliação ser pautada em indicadores qualitativos e quantitativos podendo, dessa forma, possibilitar que os sistemas de ensino passem a ter nos resultados aferidos nos processos de avaliação institucionais um condicionante para as progressões remuneratórias dos docentes.

A avaliação de desempenho, tema controverso, alimenta ainda mais polêmicas quando, sobretudo, está articula a incentivos por produtividade, que se traduzem em incrementos na composição da remuneração docente. E, ainda, é válido destacar que esse tipo de articulação entre incentivo e desempenho gera um terceiro elemento, que é a responsabilização, em caráter exclusivista, dos profissionais do magistério pelos resultados educacionais.

Quando as Diretrizes Nacionais apontam para a análise de indicadores qualitativos e quantitativos como critério para avaliação do desempenho, parece que temos a partir disso uma sugestão de que o desempenho das escolas ou dos sistemas de ensino poderão repercutir na remuneração dos professores. Para Brooke (2006), isso ocorre na perspectiva de associar consequências aos resultados sobre a crença de indução à responsabilização.

O documento final da Conae/2010 também indica a titulação como critério automático para as progressões nas carreiras. Já as Diretrizes Nacionais acrescentam a avaliação de desempenho e não fazem menção ao fato de as progressões serem automáticas.

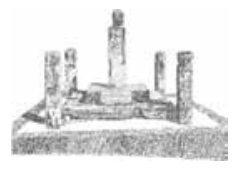


Na rede estadual de ensino do Paraná, a progressão é baseada na titulação, na habilitação profissional, na formação continuada e também apresenta uma forma de avaliação de desempenho que impacta a remuneração docente. Nessa avaliação, são considerados elementos como assiduidade, pontualidade, participação na elaboração de projetos pedagógicos das unidades em que o professor trabalha, a ética e a flexibilidade. O formulário é preenchido na escola, com a presença do colegiado e da gestão escolar. Não existe relação com o desempenho do aluno ou vinculação qualquer à avaliação do sistema de ensino, conforme sugere as diretrizes do CNE.

Pode-se questionar o sentido de uma avaliação de desempenho na qual elementos como assiduidade e pontualidade são considerados para progressão salarial do servidor, uma vez que ele, caso não seja pontual e assíduo, deve ter seus vencimentos descontados, pois deixou de cumprir sua obrigação como agente de função pública. Por que, então, premiar aquilo que deve ser a obrigação do servidor?

A promoção baseada na titulação, na rede estadual do Paraná, estrutura-se em uma parte - Especial 1 (nível médio na modalidade normal), Especial 2 (licenciatura curta) e Especial 3 (licenciatura curta com estudos adicionais) - e em três níveis: nível 1 (graduação), nível 2 (especialização lato sensu) e nível 3 (Programa de Desenvolvimento Educacional - PDE). O professor com nível médio recebe $70 \%$ do vencimento do professor graduado; o professor com licenciatura curta recebe $75 \%$ do vencimento do professor graduado; o professor com licenciatura curta e estudos adicionais recebe $85 \%$ do vencimento do professor graduado. $\mathrm{O}$ professor com especialização receberá $25 \%$ a mais que o professor graduado, e o professor participante do PDE receberá $5 \%$ a mais que o professor especialista.

Participam desses procedimentos somente os professores concursados; os contratados pelo Processo Seletivo Simplificado têm vencimento correspondente ao inicial da carreira do 
graduado; entretanto, se portarem outros títulos (especialista, mestre ou doutor), os mesmos não repercutirão em seus salários.

Outro ponto importante a ser destacado é que até o nível 2 a progressão é automática mediante a solicitação do professor em órgão competente. As progressões têm mantido regularidade e são pagas no mês de outubro de cada ano; os professores recebem retroativo ao período solicitado.

O PDE se caracteriza como mais um nível da promoção vertical na carreira dos professores da rede estadual de ensino. O programa integra as atividades de formação continuada em educação e disciplina a promoção do professor para o nível 3 da carreira, conforme previsto no Plano de Carreira do Magistério Estadual; sua regulamentação se deu por meio da Lei Complementar 130 de 2009.

Segundo a Secretaria de Educação do Estado do Paraná, o objetivo do PDE é proporcionar aos professores da rede pública estadual subsídios teórico-metodológicos para o desenvolvimento de ações educacionais sistematizadas e que resultem em redimensionamento de sua prática.

O PDE se destina aos professores estatutários do quadro próprio do magistério que se encontram no nível 2 e na classe 8 da tabela de vencimentos do plano de carreira. Para participar do PDE, os professores participam de um processo seletivo; aos aprovados, é garantido o afastamento remunerado de $100 \%$ de sua carga horária efetiva no primeiro ano e de $25 \%$ no segundo ano do Programa. O afastamento é regulamentado pela Resolução n. 4341/2007, e esses critérios são mantidos na Lei Complementar $130 / 2009$.

O PDE também possibilita o aproveitamento da titulação dos cursos de mestrado e/ou doutorado. Os professores com esses títulos passam pelo processo seletivo e devem obedecer a todos os critérios do programa; só assim os títulos serão aproveitados para a obtenção da certificação do Programa nos termos da Lei Complementar n. 103/04, artigo 11, inciso IV. Mas não existem, na

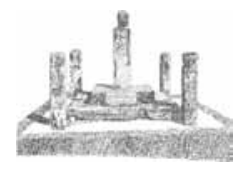


carreira do estado do Paraná, níveis que contemplem o mestrado e o doutorado.

É importante destacar que o ganho salarial para o professor que faz o PDE, inicialmente, é de 5\% sobre seu vencimento. Entretanto, esse profissional conquista a possibilidade de continuar progredindo na carreira no nível 3, que apresenta mais 11 classes (com diferença de $5 \%$ entre elas).

Para os professores da rede municipal de ensino de Curitiba, as progressões pela titulação sofreram mudanças desde a aprovação do plano de carreira em 2001 (ABREU, 2008). A carreira do magistério está dividida em parte especial, que contempla os professores com habilitação em nível médio e uma parte permanente, que está estruturada em quatro níveis (licenciatura plena, especialização, mestrado e doutorado).

A formação mínima exigida para o ingresso na carreira docente pública municipal em Curitiba é a graduação universitária. $\mathrm{O}$ graduado, ao ingressar, o faz no assim chamado nível 1. Na verdade, independentemente da formação, todos os ingressantes acabam passando pelo nível 1 por pelo menos três anos, que é o tempo de estágio probatório.

Em síntese, considerando o vencimento de cada servidor, prevalece uma diferenciação de $15 \%$ entre os níveis de formação acadêmica. Dessa forma, o profissional com uma especialização receberá $15 \%$ a mais que o graduado; o mestre, $30 \%$, e os doutores receberão $45 \%$ a mais que o graduado.

Ambas as redes apresentam condicionantes parecidos para a progressão horizontal; isto é, o procedimento que incentiva a formação continuada com aumento do vencimento do professor. As redes definem em lei que a progressão deverá ocorrer dentro do mesmo nível da carreira, ou seja, os professores avançam em classes na tabela de vencimentos da rede estadual de ensino do Paraná e em referências na tabela salarial na rede municipal de ensino em Curitiba.

\section{8}

Ano 13 - n. 16 - dezembro 2010 - p. 67-84 


\section{Considerações finais}

A forma de ingresso nas redes de ensino é diferente; na rede municipal de Curitiba, os professores ingressam por concurso público de provas e títulos, e aos que já possuem um padrão de 20 horas semanais, é permitida a dobra de jornada, por meio de um contrato de trabalho denominado Regime Integral de Trabalho. $\mathrm{Na}$ rede estadual do Paraná, além dos professores do quadro próprio do magistério, também estão presentes os professores contratados em regime especial, em Processo Seletivo Simplificado; nessa condição, são aceitos inclusive acadêmicos para o exercício da atividade de docência.

Em ambos os planos de carreira, a condição de ingresso tem sido a licenciatura plena, portanto as chamadas "partes especiais dos planos" estão em extinção progressiva, ou seja, não ocorre ingresso de novos professores nesses níveis. Entretanto, os professores que lá se encontravam na aprovação dos planos de carreira poderão progredir no mesmo nível e, também, ao concluírem a graduação, poderão passar para a parte permanente do plano e ter, ao longo do tempo, os benefícios salariais das progressões.

Em relação à evolução salarial, na comparação entre os dois planos de carreira, percebe-se que no caso da rede estadual, ao menos até o nível 2, a progressão é automática; na rede municipal, ela é condicionada a um número de vagas definido anualmente. Outra diferença é que na rede estadual de ensino do Paraná não estão contemplados os títulos de mestre e doutores, o que a rede municipal de ensino de Curitiba já contempla, em consonância às diretrizes nacionais, embora não se defenda aqui que transferir o modelo de carreira universitária para a educação básica seja o mais adequado.

Segundo as diretrizes nacionais para a carreira docente, a formação continuada é um dos elementos que podem constituirse em incentivos de progressão salarial, da mesma forma que acontece nas redes públicas analisadas.

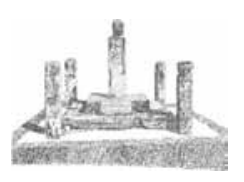


Para considerar o tempo que o profissional leva para atingir o final da carreira no caso da rede estadual de ensino do Paraná, devemos considerar que essa carreira tem uma especificidade, ou seja, até a classe 11 do nível 2, a progressão é automática; a partir daí, está condicionada à aprovação no PDE, que oferece número limitado de vagas. A previsão de final de carreira será em 15 anos para os professores que possuírem a especialização e aproximadamente 30 anos para os contemplados pelo PDE.

Na rede municipal de Curitiba, a atual estrutura de crescimento horizontal apresenta 44 referências, considerando que um professor faça todos os procedimentos (no interstício de dois anos); descontando o estágio probatório, serão necessários 91 anos para um professor ingressante chegar à última referência da tabela salarial.

Quando o tema é plano de carreira docente e seus elementos constitutivos, percebe-se uma diversidade considerável nas esferas administrativas que constituem a federação. Mesmo nos casos aqui analisados, que trataram especificamente da rede estadual do Paraná e da rede municipal de Curitiba, a diversidade na constituição das carreiras fica evidente.

O estabelecimento de princípios e diretrizes gerais para carreira e remuneração no plano federativo é, sem dúvida, o desafio que terão pela frente as entidades representativas de professores, os próprios professores, o poder público e também a comunidade acadêmica. Isso porque a melhoria das condições da carreira docente poderá, além de contribuir para a valorização do magistério, ser um importante instrumento na efetivação do direito mais amplo da educação. 


\section{Referências}

ABREU. D. C. Carreira e perfil do profissional do magistério na Rede Municipal de Ensino de Curitiba: história e impacto da política brasileira de valorização do magistério. 2008. 169 f. Dissertação (Mestrado em Educação) - Universidade Federal do Paraná, Curitiba, 2008.

Plano de cargos, carreira e salário do magistério público de Curitiba: uma análise do processo de construção da Lei n. 10.190/2001. 2005. 77 f. Monografia (Especialização em Organização do Trabalho Pedagógico) - Setor de Educação, Universidade Federal do Paraná, Curitiba, 2005.

BRASIL. Constituição (1988). Constituição brasileira, 1988. Brasília, DF: Senado Federal, 1988.

Ministério da Educação e Cultura. Lei de Diretrizes e Bases da Educação Nacional, de 20 de dezembro de 1996. Diário Oficial da União, Brasília, DF, 24 dez. 1996.

. Ministério da Educação e Cultura. Lei 9.424/96 (FUNDEF). Dispõe sobre o Fundo de Manutenção e Desenvolvimento do Ensino Fundamental e de Valorização do Magistério, na forma prevista no art. $60, \S 7^{\circ}$, do Ato das Disposições Constitucionais Transitórias, e dá outras providências, de 24 de dezembro de 1996. Diário Oficial da União, Brasília, DF, 26 dez. 1996.

Ministério da Educação e Cultura, CNE, CEB. Resolução 03/1997. Fixa diretrizes para os novos planos de carreira e de remuneração para o Magistério dos estados, do Distrito Federal e dos municípios, 1997. Diário Oficial da União, Brasília, DF, 13 out. 1997. Seção 1, p. 2298.

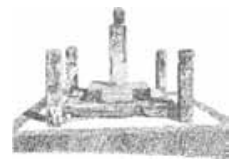


BRASIL. Ministério da Educação e Cultura, CNE. Parecer n. 10/97. Diretrizes para os Novos Planos de Carreira e de Remuneração do Magistério dos Estados, do Distrito Federal e dos Municípios, de 3 de setembro de 1997. Diário Oficial da União, Brasília, DF, 26. set. 1997.

. Ministério da Educação e Cultura, CNE. Parecer n. 09/2009. Diretrizes para os Novos Planos de Carreira e de Remuneração do Magistério Público dos Estados, do Distrito Federal e dos Municípios, de 29 de maio de 2009. Diário Oficial da União, Brasília, DF, 29 mai. 2009. Seção 1, p. 41.

. Ministério da Educação e Cultura. Resolução CNE/ CEB 02/2009. Fixa diretrizes para os novos planos de carreira e de remuneração para o Magistério da Educação Básica dos Estados, do Distrito Federal e dos Municípios. Diário Oficial da União, Brasília, DF, 20 mai. 2009. Seção 1, p. 41.

BROOKE, N. O futuro das políticas de responsabilização educacional no Brasil. Cadernos de Pesquisa, São Paulo, v. 36, n. 128, p. 377- 40, 2006.

CURITIBA. Câmara Municipal de Curitiba. Lei n. 10.190/2001. Institui o Plano de Carreira do Magistério Público Municipal. Diário Oficial do Município, Curitiba, Paraná, 28 jun. 2001.

DAVIES. N. O FUNDEF e o orçamento da educação: desvendando a caixa preta. Campinas: Autores Associados, 1999.

MELLO, M. T. L. de. Diretrizes Nacionais de Carreira: o posto e o pressuposto. Cadernos de Educação, Brasília, n. 6, jun. 1999.

SOUZA. M. Z. L. Avaliação e carreira do magistério: premiar o mérito? Retratos da escola - Escola de Formação da Confederação 
Nacional dos Trabalhadores em Educação (Esforce), Brasília, v. 2, n. 2/3, jan./dez. 2008.

TORRECILLA, J. M. Modelos innovadores en la formación inicial docente: uma apuesta por el cambio. Estudio de casos de modelos innovadores en la formación docente en la América Latina y Europa. Santiago de Chile, Junio 2006 OREALC/ UNESCO. Disponível em: <http:// unesdoc.unesco.org/ images/0014/001465/146544s.pdf>.Acesso em: 1 ago. 2011.

VIEIRA, J. D. Piso salarial profissional nacional dos educadores: dois séculos de atraso. Brasília: LGE, 2007. 


\title{
Analysis of the condition of ingress and evolution in the teaching career in the nets of state teaching of Paraná and municipal nets of teaching of Curitiba
}

\begin{abstract}
This article was developed in the ambit of the search in process entitled "Remuneration of the teachers in the public schools of basic education: configurations, impacts, impasses and perspectives". So, this work intends to realize an analysis of the teacher occupation established in the state nets of teaching in Paraná and municipal teaching in Curitiba. In the analysis, it takes priority to the categories: condition of ingress and recruitment of the teachers and the ways of salaries, progressions practiced with base in the teacher's formation. Thus, it was found that in both nets of teaching, they contains ways of ingress and discriminated salaries progressions that, in some cases, approximate themselves from which emanates the legal ordering updated by Fundeb and by new directresses for the occupation of the mastership published by National Council of Education in 2009.
\end{abstract}

Keywords: teacher's career; ingress; career development; salary; titration. 